\title{
Metamorphism Indicators for Establishing the Endogenic Fire Hazard of Coal Mining Plants in Mining
}

\author{
V. Tarasov, M. Antoshchenko, Y. Rudniev, O. Zolotarova, and N. Davidenko
}

\begin{abstract}
In coal mining, the problem of particular importance is the occurrence of endogenous fires and explosions of the methane-air mixture, which lead to the death of people. The aim of the study is to establish indicators that directly characterize the change in the elemental composition in the process of metamorphic transformations of coals and determine them tendency to spontaneous combustion. Statistical multivariate analysis showed that the degree of metamorphism is the most significant characteristic of the propensity of coal to oxidize. The sum of the content of the main components decreases inversely to the increase in carbon content over the entire range of coal conversion from a small degree of their metamorphism from coal to anthracites. The dependence of decrease in oxygen content with increased carbon is nonlinear. With carbon content of more than $88 \%$, there is a slight decrease in the rate of oxygen reduction in comparison to its decrease at earlier stages of metamorphism. A significant correlation of carbon with oxygen and hydrogen is observed. A characteristic feature of coals containing up to $75 \%$ carbon is a wide range of changes in formation moisture and oxygen content in organic matter. It indicates minor transformations of coals at the early stages of metamorphism. One of the signs of an increase in the influence of metamorphic processes is a one-sided increase in the carbon content in organic matter and a functional decrease in the sum of the remaining components hydrogen, nitrogen, sulfur and oxygen.
\end{abstract}

Index Terms - Coal, metamorphism, elemental composition, spontaneous combustion.

\section{INTRODUCTION}

In coal mining, the problem of particular importance is the occurrence of endogenous fires and explosions of the methane-air mixture, which lead to the death of people. In many cases, explosions and fires are initiated in the center of spontaneous combustion of coal [1]. As a result of long-term observations, groups of factors leading to these phenomena have been identified.

The mining-geological group of factors includes the structure and thickness of the developed layer, the angle of its incidence, the depth of mining, geothermal gradients and

Manuscript received December 22, 2020; revised May 25, 2021

V. Tarasov and M. Antoshchenko are with the Department of Mining, Volodymyr Dahl East Ukrainian National University, Severodonetsk, Ukraine (e-mail: tarasov@snu.edu.ua, antoschenko@snu.edu.ua).

Y. Rudniev is with the Department of Electrical Engineering, Volodymyr Dahl East Ukrainian National University, Severodonetsk, Ukraine (e-mail: rudnev_es@snu.edu.ua).

O. Zolotarova is with the Department of Chemical Engineering and Ecology, Volodymyr Dahl East Ukrainian National University, Severodonetsk, Ukraine (e-mail: 22helen72@gmail.com).

N. Davidenko is with the Department of Foreign Languages and Professional Communication, Volodymyr Dahl East Ukrainian National University, Severodonetsk, Ukraine (e-mail: nat.davidenko11@gmail.com). tectonic disturbance.

A group of mining and geological factors predetermines the technological operating conditions of a coal mining enterprise. The main ones are the method of opening and preparing the mine field, mining systems, methods of controlling rock pressure and maintaining mine workings, coal mining technology, its transportation, ventilation schemes for individual workings and the mine as a whole, etc.

The listed mining-geological and mining-technical factors can both contribute to spontaneous combustion and spontaneous combustion of coal in mine conditions, and slow down these processes. In addition to these indicators, the most significant group is considered to be the factors that determine the chemical activity of coal. Chemical activity is basic. This factor determines the tendency of coal to ignite spontaneously. It is due to its ability to enter into chemical interaction with oxygen [2]. Statistical multivariate analysis showed that the degree of metamorphism is the most significant characteristic of the propensity of coal to oxidation [1], [3]. In general, coal metamorphism means the sequential transformation of brown coal into coal and anthracite as a result of changes in the chemical composition, structure and physical properties of coal in the depths, mainly under the influence of elevated temperature and pressure [4]. In works [1], [3], as well as in the normative document [5], the yield of volatile substances during thermal decomposition of coals without air access $\left(V^{d a f}\right)$ was taken as the main indicator of the degree of metamorphism. This indicator has been developed and is used in the industrial classification [6] to establish the consumer properties of coals. With its help, in combination with other indicators, the heat of combustion, sintering capacity, coking capacity, the ability to obtain liquid and gaseous fuels and other consumer properties of coals are predicted. According to its physical meaning, the $\left(V^{d a f}\right)$ indicator is a product of the next artificial stage of coal conversion at elevated temperatures in laboratory conditions. The processes of coal metamorphism in natural conditions reached a certain degree of transformation of organic matter at temperatures not exceeding $650{ }^{\circ} \mathrm{C}$ [7]. Thermal decomposition of a sample of coal in laboratory conditions is carried out at a temperature of $900{ }^{\circ} \mathrm{C}$ for seven minutes [8], which significantly differs from the metamorphic transformations of mine layers in the past geological periods. The $\left(V^{d a f}\right)$ index, for these reasons, cannot comprehensively characterize the composition and properties that appeared in the process of metamorphism. Based on the total amount of gases released during thermal decomposition without their identification, it is impossible to establish the initial composition and properties of the studied coals, as it is assumed according to [1], [3], [5]. 
In parallel with the $\left(V^{d a f}\right)$ indicator, to determine the degree of metamorphism of coals, their brand identity is used [1], [3] By definition [4], a coal grade is a conventional designation of varieties of coals that are similar in genetic characteristics and basic energy and technological characteristics. According to the industrial classification [6], the grade of coal is established by the volatility index $\left(V^{d a f}\right)$, which, in turn, does not sufficiently determine the degree of metamorphic transformations. Indicators of brand identity and $\left(V^{d a f}\right)$ characterize only the consumer properties of coals, but they do not directly determine the composition and properties of fossil coals.

Based on the experience of working out of coal deposits, the influence of moisture on the oxidation of coal and its tendency to spontaneous combustion was established [1], [9]. Reservoir moisture combines moisture of various types. The state of coal with moisture equal to the maximum moisture capacity imitates the state of freshly mined coal saturated with water, from the surface of which free moisture has been removed [10]. As a consequence, the maximum moisture capacity serves as a classification parameter. In the industrial classification [6], brown coals are subdivided into types according to the value of the maximum moisture capacity. Reservoir moisture content decreases with increasing metamorphism, however, with the transition to anthracite, it increases again. The fracture of the curve is considered as the beginning of the anthracite stage of coal metamorphism [11]. According to the generally accepted definition [4], the moisture content refers to one of the criteria for establishing the degree of metamorphism of coal, but it is not considered as such in the regulatory documents [5], [12]. This is undoubtedly reflected in their quality and effectiveness of the recommended measures for the safe mining of coal seams.

It was found [13] that with an increase in the sulfur content in coal from 1 to $6 \%$, the probability of endogenous fires increases more than three times. Sulfur is contained in all types of solid fuels as various compounds in its organic and mineral parts. The total sulfur content in the organic and mineral mass of coals is considered to be the total sulfur content $\left(S_{t}^{d}\right)$ in coals and can vary from $0.2 \%$ to $10 \%[10]$.

There are main types (forms) of sulfur in coals:

- sulfate sulfur - part of the total sulfur, which is part of the inorganic mass of coal in the form of metal sulfates;

- pyrite sulfur - part of the total sulfur, which is part of the inorganic mass of coal in the form of metal disulfides (pyrite and marcasite);

- organic sulfur $\left(S_{0}\right)$ - part of the total sulfur that is part of organic compounds [10], [14].

There is no a clearly expressed pattern in the distribution of sulfur over the territory of the Donetsk basin or according to the classification characteristics of coal. Any technological group contains low-sulfur and sulfurous coals. The sulfur content does not depend on the degree of coal metamorphism, but is closely related to the content of oxygen and basic oxides that make up the ash. Coals with a lower oxygen content, as a rule, have a higher sulfur content and a predominance of iron oxides in the ash composition [14]. For the coals of the Donetsk basin, their conditional division by sulfur content into four groups is accepted:
1) low-sulfur, sulfur content up to $1.5 \%$;

2) medium-grained, $1.5 \%-2.5 \%$;

3) sulfurous, $2.5 \%-3.5 \%$;

4) high-sulfur, more than $3.5 \%$.

Of the 570 mines in Donbass, $26.4 \%$ are classified as low-sulfur, $59.2 \%$ are classified as medium and sulfurous and $14.4 \%$ are high-sulfur [15].

The analysis showed that the occurrence of endogenous fires in coal mines is fully determined by three blocks of influencing factors. The formation of mining technical factors took place at the design stage of a coal enterprise on the basis of mining and geological parameters of the occurrence of coal seams. For this reason, the technological parameters of mining for specific conditions were selected depending on the thickness of the seams, the angles of their incidence, adjacent seams - satellites and geological disturbances, etc. In this case, mining and geological conditions influenced the choice of individual technological solutions for the operation of a coal deposit. The formation of a set of mining-geological and mining-technical factors influencing the occurrence of endogenous fires in many respects occurred in a random manner. During statistical processing of the intensity of the occurred fires and forecast, their occurrence was associated with the thickness of the seams and the angles of their incidence [5], [13].

The significance of these factors in some cases contributed to the spontaneous combustion of coals, in others - they slowed down these processes. The main reason for spontaneous combustion, according to the unanimous opinion of all researchers, is the chemical activity of coals, determined by their degree of metamorphism.

Disagreements are observed in the choice of indicators of metamorphic transformations of coals and their compliance with the definition of the very concept of metamorphism. According to which, these indicators should directly reflect the changes taking place in the composition and properties of fossil coals in the past geological periods of time.

The lack of a unified approach to determining the degree of coal metamorphism when establishing the fire hazard of mine layers indicates the relevance of the considered questions.

The aim of the study is to establish indicators that directly characterize the change in the elemental composition in the process of metamorphic transformations of coals and determine them tendency to spontaneous combustion. The bulk of coals is organic matter, the composition of which is almost completely determined by the sum of the percentage of carbon $\left(C_{o}\right)$, hydrogen $\left(H_{o}\right)$, nitrogen $\left(N_{o}\right)$, sulfur $\left(S_{o}\right)$ and oxygen $\left(O_{o}\right)$. The share of other components in organic matter is usually less than one percent. The presence of moisture in the mine layers and sulfur in the mineral component also affect the occurrence of hotbeds of spontaneous combustion of coal. Considering changes in the composition of coals and the ratio between all components, one can judge the degree of metamorphic transformation of coals and their tendency to spontaneous combustion.

Determination of the degree of coal metamorphism was originally carried out to characterize the yield of coke to organic matter [11]. In the future, other indicators were established for production needs and methods for their 
determination were developed. Each of these indicators individually characterizes one of the aspects of changes in the composition and properties of coals during metamorphic processes. More than twenty such indicators are currently known. Ten of them are collectively used in the modern industrial classification [6]. With their help, the consumer properties of coal are established. First of all, they are associated with the production of coke and the production of various types of energy. The use of individual indicators of industrial classification [6] to establish the degree of metamorphism and the propensity of coal to spontaneous combustion according to [5], [12] is not scientifically justified enough. All indicators [6] characterize different aspects of the consumer properties of coals, but they are not directly related to changes in the elemental composition.

\section{METHODOLOGY}

According to the definition of metamorphism [4], one of the aspects of its manifestation is the change in the elemental composition. The bulk of the fossil coal is organic matter. Its composition is determined by the presence of five main components $\left(C_{o}, H_{o}, N_{o}, S_{o} O_{o}\right)$. The share of the remaining components of organic matter, as a rule, does not exceed one percent. The ratio of the main components of organic matter largely characterizes the degree of metamorphic transformations and determines the chemical activity of coals. One of the main signs of the intensification of metamorphic transformations of coals is a one-sided increase in the carbon content in organic matter $\left(C_{o}\right)$ and an inversely proportional decrease in the sum of the remaining components $\left(H_{o}, N_{o}, S_{o}\right.$, $\left.O_{o}\right)$. The relationship between the carbon $\left(C_{o}\right)$ content and the sum of the remaining components is inherently functional for the coals of different coal basins [16]. The correlation coefficient is almost equal to one $(r=0.995)$. This allows us to consider the carbon content in organic matter as the first step towards determining one of the sides of the metamorphic transformations of coal.

The methodology is based on the use of the elemental composition, technical and petrographic analyzes carried out earlier to establish the quality, composition and properties of coals during their processing at processing plants. Samples were taken from each wing of the mine field in all mined seams. Coals of the Donetsk basin (mines "Chelyuskinczev", “Trudovskay”, "Gagarina”, "Zasyad ko", "Ukrayna”) of low and middle stage of metamorphism of a similar petrographic composition, but different genetic types in terms of recovery, which differ by sulfur content. An analytical fuel sample was obtained after determining the external moisture of the laboratory sample, followed by grinding to a particle size of 0 to $0.2 \mathrm{~mm}$. Subsequent studies were carried out at a temperature of $900 \pm 10^{\circ} \mathrm{C}$ for coal and at a temperature of $850 \pm 10{ }^{\circ} \mathrm{C}$ for brown coal for 7 minutes. The ash content of the studied samples did not exceed $10 \%$. In this case, the conditions for determining each indicator were met according to the requirements similar to [4], [6], [8]. This made it possible in each specific case to guarantee the predetermined accuracy of determining the indicators under consideration, including the content of the main components of organic matter.

\section{RESUlTS AND DisCUSSION}

Confirmation that $C_{o}$ belongs to one of the indicators of the degree of metamorphism is its relationship with the generally accepted indicators for individual mines (Fig. 1).

With an increase in carbon content, the yield of volatile substances $\left(V^{d a f}\right)$ decreases and the vitrinite reflectance $\left(R_{o}\right)$ increases. The reservoir moisture $\mathrm{W}$ changes not so unambiguously (Fig. 1, b). With an increase in the metamorphism of coal and an increase in $C_{o}$ values, a decrease in the moisture content to minimum values is observed. Then, in the transition from coal to anthracite, a significant increase in moisture content again occurs.

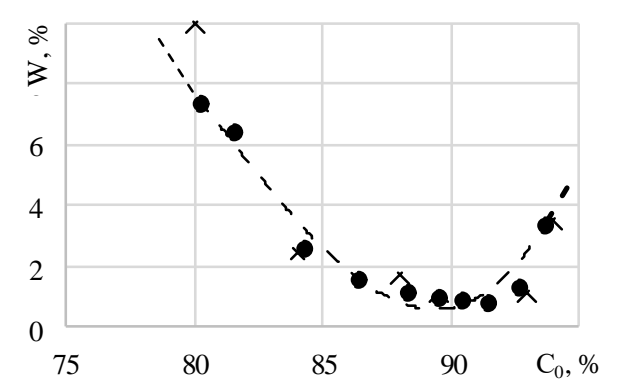

Fig. 1. Relationship between carbon content in organic matter $\left(C_{o}\right)$ with formation moisture (W).

-, $\mathrm{x}$ - experimental data on $\mathrm{W}$ changes, respectively, according to the average values in the composition of the Donets basin and individual coals.

Not only the sum of the remaining components $\left(\Sigma H_{o}, N_{o}\right.$, $S_{o}, O_{o}$ ), but also their individual content in organic matter (Fig. 2) functionally depends on the $C_{o}$ indicator.

The value of the sum of the components in most cases coincides with straight line 1 (Fig. 2, a), determined by the relationship:

$$
\Sigma H_{o}, N_{o}, S_{o}, O_{o}=100-C_{o}, \% .
$$

This indicates that $C_{o}, H_{o}, N_{o}, S_{o}, O_{o}$ determine almost one hundred percent of the composition of organic matter, and the carbon content completely controls the sum of the remaining components. The nature of changes in $H_{o}, N_{o}, O_{o}$ and their values for individual mine layers (Fig. 2) coincides with the results obtained for different deposits [16].

With an increase in the carbon content to about $88 \%$, a decrease in oxygen obeys a straight-line relationship, and at $C_{o}>88 \%$, a curvilinear one. With a carbon content of $88-94 \%$, the value of $O_{o}$ is about one percent and tends to zero with a further increase in $C_{o}$ (Fig. 2a). The hydrogen content for the considered group of mine plastics [14], [15], [17], [18] remained constant and equal to about 5\% with an increase in $C_{o}$ to $88 \%$. Then a sharp decrease was observed (Fig. 2b). The nitrogen content was practically independent of the growth of $C_{o}$. The dependence of the change in the sulfur content in organic matter $\left(S_{o}\right)$ for the considered mine layers has not been established (Fig. 2c). There is a certain tendency towards a decrease in its average values from $2.2 \%$ to $0.7 \%$ for the coals of the Donetsk basin [11]. The absence of a significant relationship between the content of total sulfur (in organic matter and mineral components) with the processes of metamorphic transformations is confirmed by 
the graph (Fig. 3). According to which there is no definite tendency of $S_{o}$ and $S_{t}^{d}$ change and depending on $C_{o}$.
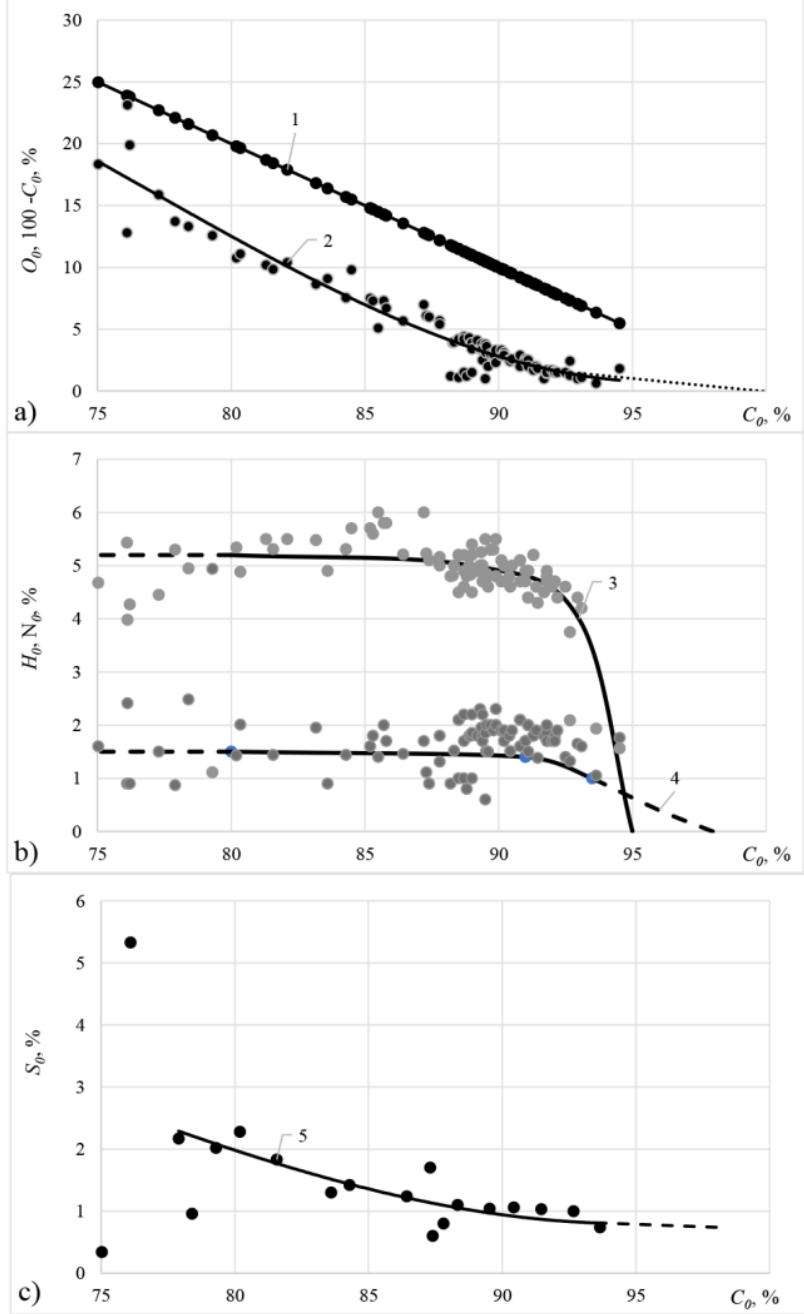

Fig. 2. Dependence of the main components of organic matter on the carbon content.

1 - direct change in the sum of the components $\left(H_{o}, N_{o}, S_{o} O_{o}\right)$ depending on $\left(C_{o}\right)$ according to equation $1 ; 2,3,4,5$ - curves of changes in the average

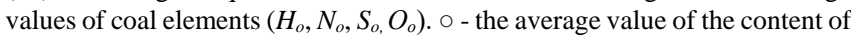
components in the organic matter of the coals of the Donetsk basin. - values, respectively, of the sum of components $\left(H_{o}, N_{o}, S_{o}, O_{o}\right)$, oxygen $\left(O_{o}\right)$, hydrogen $\left(H_{o}\right)$, nitrogen $\left(N_{o}\right)$ and sulfur $\left(S_{o}\right)$ in organic matter for individual mines.

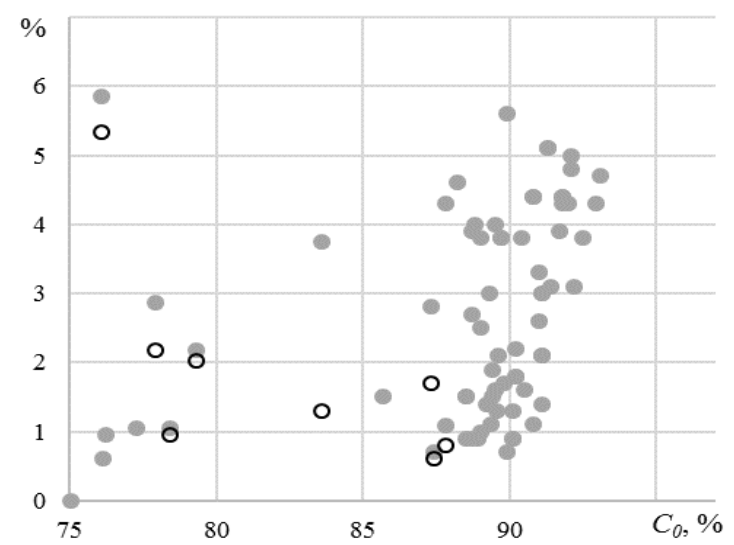

Fig. 3. Dependence of the sulfur content in coal on the carbon content $\left(C_{o}\right)$ $\circ$ - content of total sulfur in coal; $\bullet$ - sulfur content in organic matter.

The studies carried out indicate that each component of organic matter $\left(H_{o}, N_{o}, S_{o}, O_{o}\right)$ and formation moisture $\mathrm{W}$ are, to varying degrees, indicators of metamorphic transformations of mine layers.

Sulfur in organic matter $\left(S_{o}\right)$ and total sulfur $S_{t}^{d}$ do not relate to indicators of the degree of metamorphism of coals, but their content largely determines the propensity of mines to start endogenous fires [1], [5], [13]. For this reason, in the block of factors that determine the chemical activity of coals, it is necessary, together with the indicators of the degree of metamorphism $\left(H_{o}, N_{o}, S_{o}, O_{o}, \mathrm{~W}\right)$, to take into account the content of sulfur of any form of its presence in organic matter or in mineral impurities for each mine layer.

Changes in the ratio between the components of the substance and formation moisture indicate differences in the elemental composition and properties of coals. If we proceed from this position, then according to the degree of metamorphic transformations according to the average values of the constituent components, we can roughly distinguish several stages of metamorphic transformations of mine layers (Fig. 4).

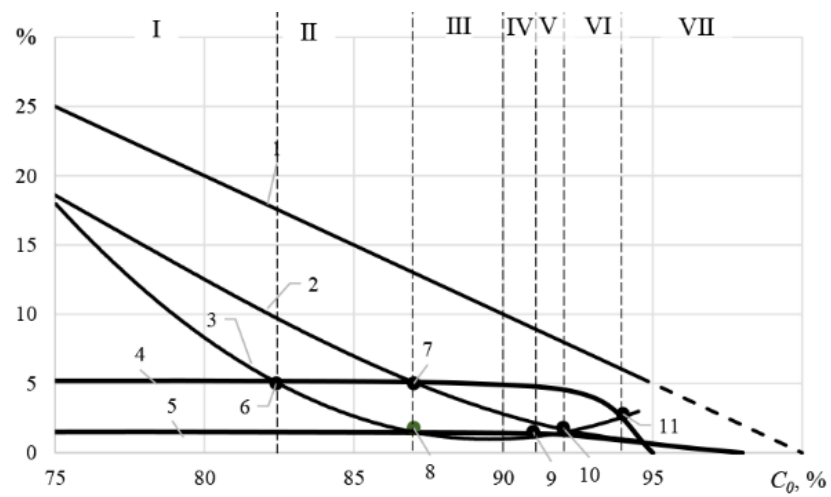

Fig. 4. Conditional separation of coal and anthracite at the stage of metamorphic transformations by the average content of components in organic matter $\left(\mathrm{H}_{0}, \mathrm{~N}_{\mathrm{o}}, \mathrm{C}_{\mathrm{o}}, \mathrm{O}_{\mathrm{o}}\right)$ and formation moisture $(\mathrm{W})$.

1 is a straight line of variation of the sum of components in organic matter according to equation. $1 ; 2,3,4,5$ - curves of changes in the average content of oxygen (2), formation moisture (3), hydrogen (4) and nitrogen (5); 6, 7, 8, $9,10,11$ - points of intersection of curves describing the change in the average values of indicators.

The carbon content in organic matter characterizes the overall depth of coal metamorphic transformation. Changing the rest of the components clarifies these transformations.

Brown coals are those with a carbon content of less than $70 \%$ in organic matter [16]. In the range of $70-75 \%$ change in $\left(C_{o}\right)$, the distinction between brown and bituminous coals is made according to the maximum moisture capacity for an ashless state [6]. In this range of $\left(C_{o}\right)$ variation, brown coals are coals with an increased content of formation moisture (from $20 \%$ or more), and the oxygen content in organic matter can exceed $20 \%$ [19].

A characteristic feature of coals with $\left(C_{o}\right)<75 \%$ is a wide range of changes in formation moisture and oxygen content in organic matter. This indicates insignificant transformations of coals in the early stages of metamorphism. At $\left(C_{o}\right)>75 \%$, changes in formation moisture (Fig. 1b) and oxygen in organic matter (Fig. 2a) acquire a regular character, which indicates an increase in the influence of metamorphic processes.

According to the average values of the components and formation moisture, the first stage of conversion of coal (I) 
should include coals with a carbon content of 75-82.6\% (Fig. $4)$. The upper boundary of this stage is determined by the point (6) of intersection of the curves of changes in formation moisture (3) and hydrogen (4). Its position on the graph indicates the presence of changes in the composition and properties of coals when the ratio between the content of formation moisture and hydrogen changes.

The upper limit of stage II is determined by points 7 and 8 at $C_{o}=87.0 \%$. They were obtained at the intersection of curves 2, 4 and 3,5, respectively, which is also evidence of a change in the composition and properties of coals.

The upper boundary of stage III (point 9) is set according to the minimum value of the formation moisture content (curve 3), which conventionally separates coal and anthracite at $C_{o} \approx 91.5 \%$. Point 10 of the intersection of the curves for the change in the average values of oxygen (2) and nitrogen (5) determined the upper limit $C_{o} \approx 92.2 \%$ ) of stage IV.

Stage $\mathrm{V}$ is limited by the point of intersection (11) of the curves of changes in the average values of formation moisture (3) and hydrogen (4). Stage VI is characterized by the minimum oxygen content in organic matter (up to $0.2 \%$ ) and the maximum value of formation moisture (up to $3.3 \%$ ).

The least studied stage in terms of the content of components is still stage VII at $\left(C_{o}\right)>95 \%$. The possible oxygen content tends to zero. The main components of metamorphic transformations for this case are the content of nitrogen (up to $1.0 \%$ ) and hydrogen (up to $0.9 \%$ ) in organic matter. It is not possible to establish the content of formation moisture at the final stage of coal metamorphism (VII) on the basis of the known literary sources. Based on the average carbon values at this stage $(97.5 \%)$, then the sum of the remaining components of organic matter should not exceed $2.5 \%$.

Approximate limits of changes in the components of organic matter $\left(H_{o}, N_{o}, C_{o}, O_{o}\right)$ and formation moisture $(\mathrm{W})$ at different stages of metamorphic transformations of coal are shown in Table 1. According to their average values for each stage, ranks of components are compiled, which comprehensively characterize the degree of transformation of mine layers.

In these ranking series, there is no sulfur content in organic matter $\left(S_{o}\right)$, since its presence is not an indicator of the degree of metamorphic transformations of coals in general and mine layers in particular. This is confirmed by the absence of any regularity in the change in the average sulfur content in organic matter ( $\bar{S}_{0}$ ) for different stages of metamorphic transformations (Table 1).

For stage I the value $\bar{S}_{0}$ is $2.5 \%$, and for VI it is $2.8 \%$. For the remaining stages of metamorphism (II-V and VII), the average sulfur content in organic matter is in the range of $0.4-1.3 \%$, which allows all coals of these stages to be classified as low-sulfur [14], [15]. Despite such an uncharacteristic distribution of the average sulfur content in organic matter in the considered private sample of coal mines, its presence significantly influenced the ranking of all components, including those determining the propensity of coal to spontaneous combustion. With a higher sulfur content in organic matter for individual mines (up to 5 percent and more), which is observed in most cases [15], their individual ranking series of organic matter components may differ significantly from the ranking series of average values. In them, the leading place can be occupied by the components that determine the propensity of coals to self-combustion $\left(O_{o}\right.$, $\mathrm{W}$ and $S_{o}$ ), which can significantly affect the intensity of endogenous fires during the development of individual mines. If we take into account four groups of possible sulfur content in organic matter at each stage of metamorphism (there are at least seven of them), then from all mine layers, according to the ranking of components, about three dozen distinguishing features can be distinguished.

TABLE I: STAGES OF COAL METAMORPHISM ACCORDING TO THE CONTENT OF THE MAIN COMPONENTS IN ORGANIC MATTER

\begin{tabular}{|c|c|c|c|c|c|c|c|}
\hline \multirow{2}{*}{ 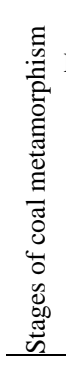 } & \multicolumn{5}{|c|}{ Limits of variation of components / average values, $\%$} & \multirow{2}{*}{\multicolumn{2}{|c|}{ 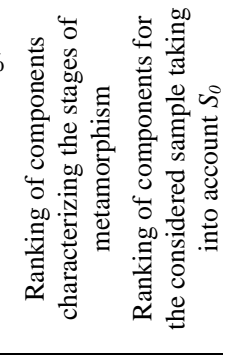 }} \\
\hline & $C_{0}$ & $O_{0}$ & $W^{*}$ & $H_{0}$ & $N_{0}$ & & \\
\hline & 82.6 & 8.5 & 5.2 & 5.2 & 1.5 & \multirow{2}{*}{$\begin{array}{c}C_{0}, O_{0}, W \\
H_{0}, N_{0}\end{array}$} & \\
\hline & 78.8 & 12.0 & $\overline{8.8}$ & $\overline{5.2}$ & 1.5 & & \\
\hline & $82.6 \div 87.0$ & $8.5 \div 5.2$ & $5.2 \div 1.5$ & 5.2 & 1.5 & \multirow{2}{*}{$\begin{array}{c}C_{0}, O_{0}, H_{0} \\
W, N_{0}\end{array}$} & \\
\hline & 84.8 & 7.2 & 3.4 & $\overline{5.2}$ & $\overline{1.5}$ & & \\
\hline & $87.0 \div 91.5$ & $5.2 \div 1.8$ & $1.5 \div 0.8$ & $5.2 \div 4.3$ & 1.5 & \multirow{2}{*}{$\begin{array}{l}C_{0}, H_{0}, O_{0}, \\
\quad N_{0}, W\end{array}$} & \\
\hline & 89.3 & 3.5 & 1.2 & 4.8 & $\overline{1.5}$ & & \\
\hline & $91,5 \div 92,2$ & $1.8 \div 1.4$ & $0.8 \div 1.3$ & $4.3 \div 3.8$ & $1.5 \div 1.4$ & \multirow{2}{*}{$\begin{array}{l}C_{0}, H_{0}, O_{0} \\
\quad N_{0}, W\end{array}$} & $C_{0}, H_{0}$, \\
\hline & 91,9 & 1.6 & 1.1 & $\overline{41}$ & 15 & & $\begin{array}{l}p_{0}, N_{0} \\
W\end{array}$ \\
\hline & $92,2 \div 93,2$ & $1.4 \div 0.6$ & $1.3 \div 2.3$ & $3.8 \div 2.3$ & $1.4 \div 1.2$ & \multirow{2}{*}{$\begin{array}{c}C_{0}, H_{0}, W \\
\quad N_{0}, O_{0}\end{array}$} & $C_{0}, H_{0}$, \\
\hline & 92,7 & 1.0 & 1.8 & 3.1 & 1.3 & & $\begin{array}{l}\rho_{0}, S_{0} \\
\rho_{0}\end{array}$ \\
\hline \multirow{2}{*}{ VI } & $93,2 \div 95,0$ & $0.6 \div 0.2$ & $2.3 \div 3.3$ & $2.3 \div 0.9$ & $1.2 \div 1.0$ & \multirow{2}{*}{$\begin{array}{c}C_{0}, W, H_{0} \\
\quad N_{0}, O_{0}\end{array}$} & $C_{0}, W$, \\
\hline & 94,1 & 0.4 & 2.8 & 1.6 & 1.1 & & $\begin{array}{l}0_{0}, \Pi_{0} \\
V_{0}, O_{0}\end{array}$ \\
\hline VII & $\frac{95.0 \div 100}{97,5}$ & 0.2 & $-* *$ & 0.9 & 1.0 & $\begin{array}{c}C_{0}, N_{0}, H_{0} \\
O_{0}\end{array}$ & $\begin{array}{c}C_{0}, N_{0} \\
H_{0}, S_{0} \\
O_{0}\end{array}$ \\
\hline
\end{tabular}

Note: * - formation moisture content;

$* *$ - according to the known literature data, it is not possible to set the value of formation moisture in the range of change $C_{0}=95 \div 100 \%$

At present, all mine layers are divided [12] into only three fire hazard groups. The paper [13] does not consider the effect of the type of sulfur content on the probability of spontaneous combustion of coals. In the presence of moisture, rapid self-heating of coals with a sulfur content in pyrite compounds is observed [1]. For this reason, when establishing the tendency of coals to self-heating and spontaneous combustion, it is necessary to take into account all types of sulfur. A significant part of it can be found not in organic matter, but in mineral compounds. In some cases, the content of sulfur in the mineral part exceeds its presence in organic matter, which must be taken into account when determining the tendency of coal to spontaneous combustion.

The change in the elemental composition of organic matter characterizes only one side of the metamorphic transformations of coal. For a more complete characterization of coals, it is additionally necessary to involve the results of technical and petrographic analyzes. 
They take into account, in addition to the composition of organic matter, ash content, moisture and petrographic composition of the studied coal samples. These indicators are determined, depending on their purpose, for a different state of the samples. Samples can be prepared for dry or dry ash-free mass, which does not correspond to the state of coal in mine layers during mining operations. For example, considering the moisture of the analytical sample $W^{a}$, it is impossible to judge the formation moisture $(W)$ of the mine formation [10]. To reliably determine the propensity of coal mines to spontaneous combustion, it is necessary to take into account the existing differences between the laboratory determination of indicators and the conditions for finding coal in production conditions [2].

This will maximize the accuracy of predicting the chemical activity of coal during mining operations.

\section{Conclusion}

In coal mining, the problem of particular importance is the occurrence of endogenous fires and explosions of methane-air mixture, which lead to the death of people. In many cases, explosions and fires are initiated in the hotbed of spontaneous combustion of coal. Statistical multivariate analysis showed that the occurrence of endogenous fires occurs with some combination of three blocks of influencing factors. Their parameters are determined by the mining and geological and mining technical conditions of the development of mine layers and the chemical activity of coals.

The study of the elemental and technical analysis of coals made it possible to identify characteristic features, with a carbon content of up to $75 \%$, a wide range of changes in formation moisture and oxygen content in organic matter is observed, which indicates insignificant transformations of coals at the early stages of metamorphism. With a further increase in the carbon content, changes in the values of formation moisture and oxygen in organic matter are observed and they acquire a regular character, which indicates an increase in the influence of metamorphic processes.

It is shown that in order to reliably establish the manifestation of the hazardous properties of mine layers during mining, it is necessary, in addition to the industrial classification, to consider indicators that can directly characterize such properties. These include changes in the elemental composition, mineral impurities and moisture in the entire range of coal metamorphism series.

\section{CONFLICT OF INTEREST}

The authors declare no conflict of interest.

\section{AUTHOR CONTRIBUTIONS}

Tarasov V. supervised the analysis and wrote the paper, Antoshchenko M. and Rudniev Ye. contributed data collection and analysis, and reviewed the paper. Zolotarova O. and Davidenko N. assisted data analysis.; all authors had approved the final version.

\section{ACKNOWLEDGMENT}

The authors express their sincere gratitude to Volodymyr Dahl East Ukrainian National University for support in conducting research.

\section{REFERENCES}

[1] M. Onifade and B. Genc, "A review of research on spontaneous combustion of coal," International Journal of Mining Science and Technology, vol. 30, no. 3, pp. 303-311, May 2020.

[2] A. R. Gbadamosi et al., "Analysis of spontaneous combustion liability indices and coal recording standards/basis," International Journal of Mining Science and Technology, vol. 30, no. 5, pp. 723-736, September 2020.

[3] O. Moshood, B. Genc, and S. Bada, "Spontaneous combustion liability between coal seams: A thermogravimetric study," International Journal of Mining Science and Technology, vol. 30, no. 5, pp. 691-698, September 2020

[4] GOST 17070-2014, (ISO 1213-2:1992, NEQ) Coals, Terms and Difinitions.

[5] Mine Safety: Proceedings of the 27th International Conference of Safety in Mines Research Institutes, Select Papers, New Delhi, 20-22 February, 1997.

[6] GOST 25543-2013, "Brown coals, hard coals and anthracites. Classification according to genetic and technological parameters," Official Publication. Standartinform, Moscow, Russia.

[7] J. Deng et al., "Study on coal spontaneous combustion characteristic temperature of growth rate analysis," Procedia Engineering, vol. 84, pp. 796-805, 2014

[8] ISO 562:2010 Hard Coal and Coke - Determination of Volatile Matter.

[9] H. Wang, B. Z. Dlugogorski, and E. M. Kennedy, "Role of inherent water in low-temperature oxidation of coal," Combustion Science and Technology, vol. 175, no. 2, pp. 253-270, 2003.

[10] Q. Zhu, "Coal sampling and analysis standards," IEA Clean Coal Centre, London, United Kingdom, 2014.

[11] V. A. Uspenskij, "The experience of the material balance of the processes occurring during the metamorphism of coal seams," Petroleum Geology - Theoretical and Applied Studies, no. 1, pp. 1-10, 2006.

[12] KD 12.01.401-96 Endogenous fires in the coal mines of Donbass, Prevention and suppression. Instructions. Official publication, NIIGD, Donetsk, UA.

[13] Z. H. A. N. G. Weiqing et al., "Study on coal spontaneous combustion characteristic structures affected by ionic liquids," Procedia Engineering, vol. 26 pp. 480-485, 2011.

[14] D. Misch et al., "Light and trace element composition of Carboniferous coals from the Donets Basin (Ukraine): An electron microprobe study," International Journal of Coal Geology, vol. 168, part 1, pp. 108-118, November 2016.

[15] M. A. A. Ahamed et al., "Coal composition and structural variation with rank and its influence on the coal-moisture interactions under coal seam temperature conditions - A review article," Journal of Petroleum Science and Engineering, vol. 180, pp. 901-917, 2019.

[16] N. I. Antoshhenko and V. D. Shepelevich, "Methane in coal seams from formation to emission," Alchevsk: DonGTU, 2006, p. 267.

[17] M. Onifade and B. Genc, "Comparative analysis of coal and coal-shale intrinsic factors affecting spontaneous combustion," International Journal of Coal Science \& Technology, vol. 5, no. 3, pp. 282-294, September 2018.

[18] M. Onifade, B. Genc, and N. Wagner, "Influence of organic and inorganic properties of coal-shale on spontaneous combustion liability," International Journal of Mining Science and Technology, vol. 29, no. 6, pp. 851-857, December 2019.

[19] W. M. Guo et al., "Geochemistry of palaeogene coals from the fuqiang mine, hunchun coalfield, northeastern China: Composition, provenance, and relation to the adjacent polymetallic deposits," Journal of Geochemical Exploration, vol. 196, pp.192-207, January 2019.

Copyright (C) 2021 by the authors. This is an open access article distributed under the Creative Commons Attribution License which permits unrestricted use, distribution, and reproduction in any medium, provided the original work is properly cited (CC BY 4.0). 


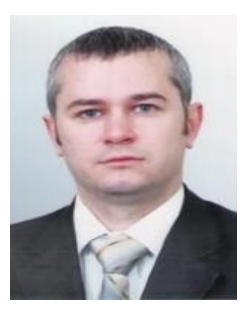

Vadym Tarasov is an associate professor in the Department of Mining at Volodymyr Dahl East Ukrainian National University. He obtained his Ph.D. in chemical engineering (2007) from the Lviv Polytechnic National University, Ukraine, and the MSc. (2003) from Volodymyr Dahl East Ukrainian National University, Ukraine. His research interests include heterogeneous catalysis, spontaneous combustion and environmental applications.

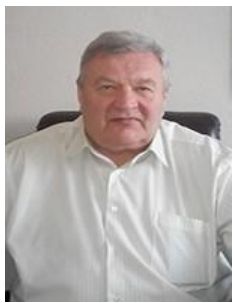

Mykola Antoshchenko graduated from Donetsk Polytechnic Institute (1973). He defended his doctoral dissertation (2004), professor (2006). He worked in 1973-83 at the Makeyevka Research Institute. From 1983 to 1994 he held the positions of the head of the section, deputy chief engineer, chief engineer and director and enterprises of the production association "Donbasantratsit". From 1998 to 2006 he was the dean of the branch Donbass Mining and Metallurgical Institute in Krasny Luch. 2006-2010 Chairman of the City Council of Krasny Luch. 2011-2018 Head of the Department of Labor Protection and Rector of DonSTU. From 2018 to the present - Head, Professor of Mining Volodymyr Dahl East Ukrainian National University, Ukraine. His research interests include forecast and management of gas emissions in coal mines.

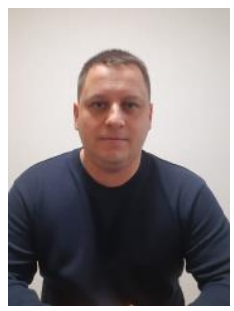

Yevhen Rudniev is the head of the Department of Electrical Engineering at Volodymyr Dahl East Ukrainian National University. He obtained his Ph.D. in electrical engineering (2013) from National Technical University «Kharkiv Polytechnic Institute» Ukraine, and MSc. (2008) from Donbass State Technical University, Ukraine. His research interests include adjustment of energy efficiency of technological processes by means of an electric drive and modernization of the electric drive and distribution of control systems.

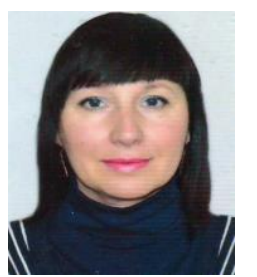

Olena Zolotarova was born in Saint Petersburg on November 22, 1972. In 2005, she got her master's degree in chemical engineering from Ukrainian Engineering Pedagogics Academy, Sloviansk, Ukraine. In 2016, she received the academic degree of doctorate of philosophy in educational sciences in SE "Luhansk Taras Shevchenko National University". From 2005 to 2016 she worked as a lecturer at Ukrainian Engineering Pedagogics Academy, Slovyansk, Ukraine. Since 2016 he has been working as an Associate Professor of the Department of
Chemical Engineering and Ecology of Volodymyr Dahl East Ukrainian National University, Severodonetsk, Ukraine. In 2019, she underwent an internship at Cuiavian University in Wloclawek (Republic of Poland) in the specialty of "Technical Sciences". The main works that have been published recently are "Study of the patterns of ammonium nitrogen removal of wastewater from chemical production by deposition", "Analysis of metamorphism and tendency of black coals to spontaneous combustion", "Selection of classification indicators to characterize the hazardous properties of coal mines". Utility model patents: "Method of obtaining lime", "Method of carbonization of ammoniated brine", "Method of obtaining granular urea". The scientific activity focuses on the research in the field of mineral fertilizers for the needs of agriculture; pedagogical direction is connected with the formation of students` value orientations in the process of educational work.

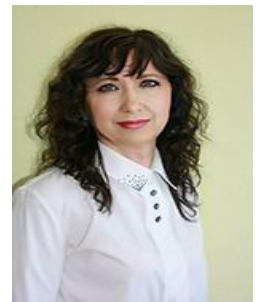

Nataliia Davidenko is a senior lecturer of the Department of foreign languages and professional communication, Volodymyr Dahl East Ukrainian National University. She was born on March 26, 1962 in Severodonetsk, Lugansk region. In 1979 she finished secondary school and entered in Izmail Pedagogical State University. In 1985 she graduated it and got specialist, teacher of French language and English language.

She has more than 25 years of teaching and research experience. Basic courses taught: Foreign language (English, French) Business foreign language (English, French) Foreign language by trade (English, French). Scientific activity (directions of scientific research) - Features of teaching a second foreign language in higher education, Features of teaching a foreign language in France, IT technology in higher education. Qualification courses 2017-2018 - British Council English program for Universities project -114 hours.

Publications: Language education in the XXI century: methodology, theory and practice: monograph / N.O. Barvina, L.E. Belovetskaya, N.O. Davidenko, O.I. Kozmenko, O.E. Krsek, N.S. Sidash, T.G. Solopova ISBN 978-617-11-0093-0. C.32-52 (total p.160) Karpyuk L.V., Davidenko N.A."COMPUTER PRACTICE IN ENGINEERING GRAPHICS"BULLETIN OF Volodymyr Dahl East Ukrainian National Univer-sity No 4 (260) 2020 p. 29

"Translation as a dialogue of cultures" All-Ukrainian scientific conference of the Department of Translation of SNU. Further "Language and literature in the context of culture and intercultural communication." April 2016 SNU m. V. Dalya, - p.25. 